\title{
Creating a Choose-Your-Own-Adventure Library Orientation: The Process of Using a Text-Based, Interactive Storytelling Tool to Take Your Orientation Virtual
}

\section{Amber Sewell}

The University of Tennessee, Knoxville

Abstract: When in-person instruction was taken off the table, a new virtual orientation to the library

was needed. Striving to create a balance of informational and engaging content, this article describes the thought- and creation-process behind a choose-your-own-library-adventure game built with the online tool Twine, and includes feedback and revisions made based on the Fall 2020 semester.

Keywords: library orientation, gamification, instructional design, academic libraries, innovation, outreach

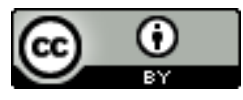

This is an Open Access article distributed under the terms of the Creative Commons Attribution 4.0 International License (http://creativecommons.org/licenses/by/4.0), which permits unrestricted use, distribution, and reproduction in any medium, provided the original work is properly cited. 
Library one-shots for first-year and transfer students are a great way to introduce new students to their academic library. Often taking place their first semester during an orientation seminar, these one-shots bring students into the physical space and give them face-to-face time with librarians in an effort to demystify libraries and demonstrate how the people, services, and resources at the library can make their time as university students easier. At the University of Tennessee, Knoxville, library orientation for first-year seminars was an engaging group activity that not only introduced students to online resources, but prioritized orientation to the physical space, taking students to key service points to help reduce library anxiety, as well as introducing librarians as helpful, approachable individuals with a genuine desire to help students with their work.

\section{Previous Activity}

Employing active learning and using common game design elements, the Fall 2019 iteration of the first-year one-shot divided students into teams and presented them with a series of timed challenges. Using the university's mascot, the dog Smokey, as a theme, students were given a brief tour of the library's website and an overview of how to locate a book or article; then, teams were given a worksheet to complete using this information. Once the completed worksheet was turned in, teams were sent out into the library to one of five or six important service points. These locations were all marked by Smokey, with a sign that gave students some quick facts about their service point. Students would come together at the end of the game to share what they had learned.

This design accomplished several goals. It familiarized students with the process of locating online materials, introduced them to the chat feature, and prompted them to explore the physical space in a low-stakes team environment. Initially competing against each other, the teams came together at the end of class to tell their peers about the service location they had visited, creating a 
larger group experience. This one-shot also allowed students to interact with a librarian in an engaging, informative manner that hopefully served to reduce their anxiety when approaching a librarian for help in future interactions.

This game became one of my responsibilities when I accepted a position as Teaching \& Learning Librarian in November 2019, which includes liaison duties to our First-Year Programs department on campus. Though our university does not have many sections of the First-Year Studies course in the spring semester, my goal was to evaluate the game design and make some changes for the upcoming Fall 2020 semester. Then COVID happened.

\section{Considerations for Creating a New Activity}

Like many higher education institutions, we were unsure what instruction would look like in the fall. As summer shortened, it became clear we would need an online alternative to ensure the safety of our students, faculty, and staff. The new challenge was to create a fun, online alternative to our in-person activity that did not add to the Zoom burnout so many students-and instructors-were facing; not only that, it needed to be as accessible to students as possible, and still function as an introduction to physical spaces for those who opted to visit campus. It required re-evaluating the goals of an orientation and using a practical mindset to account for how students were likely feeling heading into another majority-online learning environment. When sitting down to create this new activity, I had four chief factors to keep in mind: burnout, engagement, mode of delivery, and allowing students to choose what would be relevant to their learning journey.

\section{Burnout}

The first practical consideration I wanted to keep in mind was that for the fall semester, students and instructors alike were likely feeling burnt out. Not only had a global pandemic ushered in 
the new year, but racial injustices across the nation drew attention during the summer, and the approaching presidential election was on the horizon. On top of that, the spring semester had featured a rapid shift to online learning, with mixed results.

When factoring these conditions into my game design, I realized whatever I created would need to assume very different motivations than could previously be relied upon. People were working with much lower levels of energy. Burnout also meant that attention spans would be shorter. While a fun theme in the physical library is often enough to engage students in-person, trying to replicate that experience over Zoom-here cameras are optional, students' physical environments may not be conducive to concentrating, and none of the information being conveyed is immediately relevant to an assignment-would simply not be effective.

\section{Engagement}

I often incorporate game design elements into instruction when possible. This is especially important when teaching courses where the information students are receiving is not directly tied to an assignment, as is usually the case with these first-year one-shots. To capture their attention and provide motivation, structuring the class as a game gives student learning meaning (Smale, 2011; West \& Witt, 2020). For this new virtual orientation to the library, creating a fun, engaging experience for students felt vital to its success. To create a student-centered design, I needed to keep in mind the why: Why would students feel compelled to complete this exercise? Of course, I was hoping they would learn how to use the library and its resources, but I was also hoping they would have fun doing so. Additionally, I hoped that having a fun assignment would help momentarily alleviate some of the burnout students were experiencing; by giving them a game as an assignment, it was switching things up from a more traditional lecture format. 


\section{Mode of Delivery}

Providing a fun experience that did not actively contribute to student and instructor burnout also led me to choose an asynchronous activity rather than attempting to facilitate a game in Zoom. I myself had experienced how wildly my energy stores could fluctuate throughout the day, and I wanted to give my game the best possible chance to achieve its objectives. That meant offering an asynchronous activity that students could complete whenever they felt best able to concentrate. This also meant that instructors would have more flexibility in assigning the game; rather than choosing a time where all students would need to be available to participate, instructors could instead post a link to the game and give students a deadline.

\section{Allowing Learners to Choose What Is Relevant}

Finally, with fluctuating energy reserves, unpredictable attention spans, and a desire to support student agency, I wanted students to have control over the learning journey. Some information was important for all students to learn (e.g., that the physical library was open, how to chat in for help, that all research assistance would take place over Zoom and how to sign up), whereas other pieces of information were nice-to-know, rather than need-to-know (e.g., those service points students would visit in the in-person game). In a time of online learning where it might feel like much was out of their control, I wanted to give students a sense of agency and competence; they knew what their areas of interest were, and the game trusted them to explore the resources that would best benefit them in the moment. I also did not want to overwhelm students with information, so presenting students with the initial choice of either coming into the library or using online resources only was important to filter out unneeded information. 
These four considerations shaped the game design immensely. Looking at what I wanted to achieve, a choose your own adventure style game seemed most appropriate, especially in creating an activity that gave students agency over their learning process.

\section{The Process}

Twine (http://twinery.org/) is an interactive text-based storytelling tool. Though it is mostly used outside of academia, Hare and Evanson (2018) used Twine to create an outreach experience for undergraduate students to illustrate what information privilege is and what it looks like. Playing Hare and Evanson's information privilege game made using Twine after reading their article, I was struck with how Twine could be used to create an interactive experience that drew players into the story. Twine stories are built with a series of passages; internal links allow players to navigate through the story in a non-linear manner. By writing a story in second person and using the internal links to represent different choices available to the player, Twine created a more personal experience than other forms of tutorials.

Having identified a format and a tool, I set out to storyboard the experience. Creating a storyboard is an important way to ensure the progression of the game makes sense before actually beginning to build the game. In this case, I sat down with a notebook and divided a page into two sections, one for in-person gameplay and one for distance students. From there, I sketched out roughly the route I envisioned players taking; what events or conversations would happen, and in what order? It was a very simple storyboard, just a couple of keywords for each event and arrows showing the possible progression routes players could take. The game premise would be simple: students have a research assignment they need to complete and have come to the library for help. To determine which type of information would be most relevant to the student, they would first choose whether or not they 
were coming to the physical library. Based on that decision, they were presented with a series of library resources and services that might fit their needs. All students who went the in-person route would learn about social distancing guidelines put in place, with images of study spaces and students wearing masks to give them visual confirmation of what to expect when they entered the library. Students would also approach the public service desk and interact with a librarian, schedule and attend a virtual research consultation, learn about the series of instructional workshops being hosted each week of the semester, and learn how to find sources using either the library's online catalog or a scholarly database. Throughout the game, this first path allowed students to explore how to locate a book in the stacks and check it out, what services at our multimedia lab were available, how to use a course research guide, and how to book a study room.

For the second path, students could explore library resources and services in a distance learning environment. With this route, students learned how to use the chat function, find eBooks and articles online, schedule a virtual research consultation, and how to register for the online instructional workshops. Optional paths for this route included how to request PDF scans of materials in the physical library, how to use interlibrary loan, and how to use the multimedia studio's online resources to create projects.

With a storyboard in place, I began to build the game. I have a tendency to dive into a project with little to no background; in this instance, I had almost zero coding experience. Twine is extremely user friendly, however, and I was able to build a functioning game pretty easily, even incorporating several images and external links. Each path heavily relied on images to either show students what the spaces inside the library looked like or provide screenshots to walk students through a process such as booking a study room or finding an article. Whenever possible, I provided links to information that 
might be subject to change, like building hours or partners within the library and their operations, to limit updates I would have to make to the game.

Because I did not do much investigation before building, though, it was not the smoothest of processes. I used the online version of Twine initially, not understanding that my game could disappear simply by clearing my browser history. I Googled anything I could not figure out, like how to add images, provide external links, and change background, font, and link colors. I did not understand the difference between HTML and CSS, and I was not sure what an HTML file was or how I would make the game accessible. Despite these barriers, with lots of copying and pasting, I was able to create a testable version of the game.

While it was out for testing with other members of the Teaching \& Learning Programs department, as well as other departments within the library whose services I included (the Learning Commons, our multimedia lab the Studio, and Special Collections), I tasked myself with adding more images. For a reason I could not comprehend, only some of the images I added to the game worked. I was using a convoluted process that involved converting my images to Base64, then copying and pasting that ridiculously long code into my Twine passage. This had not been the first solution to come up when I Googled the process, but the other solutions mentioned some sort of file structure that sounded too intimidating to figure out.

Finally, I became frustrated enough to do what I should have done in the beginning: I watched some tutorials. Two days before classes started, which was my deadline for getting the game uploaded, I visited blog posts written by Hammond (n.d.; 2017) about beginner HTML/CSS and beginner Twine. Not having learned my lesson, I attempted to dive straight into the Twine guide, but was quickly forced to backtrack and start at the beginning, with his HTML guide. 
Working through these tutorials was a turning point, opening up more possibilities of what I could achieve with Twine and helping me understand some of what all my copying and pasting had been doing. I learned so much, in fact, that two days before it was due to launch, I remade the game from scratch, following Hammond's tutorials. Not only did all of my images now work, but I was also able to personalize the game even more. I added a text box so players could enter their name when they first speak to a librarian, which enabled the game to refer to the player by name throughout the simulated conversations. I was also able to add some code that detected whether students had opted to set up a virtual consultation earlier in the game; at a later point, when students hit a wall and need help finding more sources, the game would either show them how to log into the consultation they'd set up earlier, or prompt them to schedule one.

Down to the wire, I sent the HTML file containing my game to our instructional designer and one of our online learning librarians to publish to our tutorials page. After a final check that all of the images showed up and all the links led to where they were supposed to go, we made it public, and I emailed the announcement to the first-year programs faculty.

\section{Feedback}

I received a good amount of feedback from students and library faculty and staff who played the game throughout the fall semester. One issue I knew I would have to fix was resizing the images; on a laptop they were okay, but on mobile, they were just too large. I also realized a couple of months into the game that I could have looked into a way to track players' progress throughout the game-could I use a tool like Google Analytics to see how many times each passage was visited? Both of these changes, though, were small enough to wait until the update for Spring 2021. 
Student feedback—both from the online assessment I added in the final passage of the game and from a couple of classes where the game was used synchronously-was overwhelmingly positive. Students appreciated the conversational, informal nature of the game; the interactive nature of Twine helped them feel engaged and active in the learning process, and several responses said they appreciated the many options available. Walking players through the step-by-step processes-how to look up a map to a book and find it in the library, or how to get to an eBook-were cited as the most valuable parts of the game. I had worried that these multiple screenshots would take up too much screen time, but it was clearly worth the effort.

\section{Revisions}

In considering changes for the spring update, I knew I wanted to resize the images and try to gather more data about game play. Checking back with my partners at the Commons and the Studio, only one adjustment needed to made in the representation of their services; lots of students had chatted in using the library's online ask a librarian service asking about large format poster printing at the Studio, so that information was added to the game. Finally, I had been thinking about accessibility and reached out to our international student liaison, who had helpful suggestions about making a more accessible version of the game for students who speak English as a second language (E2L).

Resizing the images was tedious, but worked fine, although our instructional designer had to upload three versions of the game before I got it right. After combing the internet and consulting Reddit, there does not currently appear to be a way to track traffic to individual passages; it remains on my radar but was not the highest priority. As for the E2L-friendly version of the game, it is currently in its draft form; once finalized, we will promote it through the university's International House. The international student liaison and I look forward to seeing the results of that assessment. 


\section{Conclusion}

With my small amount of game design experience, I feel this choose-your-own-library-

adventure game (https://tiny.utk.edu/using-ut-library) is the best alternative to an in-person

orientation I could have created for students in our current environment and will serve as a great

alternative when in-person instruction resumes for those instructors who are unable to physically bring their class to the library. I wanted an informative, engaging game that provided the students with useful information in a low-stakes way, avoiding adding to their Zoom burnout. Twine proved to be the perfect vehicle for delivering this experience, and while I have games in the works with other tools, I am excited to see where else I can take information literacy instruction with this tool.

\section{References}

Hammond, A. (n.d.). A total beginner's guide to Twine 2.1. ttp://www.adamhammond.com/twineguide/ Hammond, A. (2017, February 20). A total beginner's guide to HTML and CSS. http://www.adamhammond.com/htmlguide/

Hare, S. \& Evanson, C. (2018). Information privilege outreach for undergraduate students. College \& Research Libraries, 79(6), 726-736. https://doi.org/10.5860/crl.79.6.726

Smale, M. (2011). Learning through quests and contests: games in information literacy instruction. Journal of Library Innovation, 2(2).

West, B. K. \& Witt, A. (2020). Challenge, fantasy, and curiosity: Activating students' intrinsic motivation within information literacy sessions. The Journal of Creative Library Practice. https://creativelibrarypractice.org/2020/08/31/challenge-fantasy-and-curiosity-activatingstudents-intrinsic-motivation-within-information-literacy-sessions/ 